\title{
Correlating the solubility of supercritical gases in high molecular weight substances using a density-dependent equation
}

Elvis J. Hernández, Guillermo Reglero and Tiziana Fornari*

Sección Departamental de Ciencias de la Alimentación.

Universidad Autónoma de Madrid, 28046 Madrid, Spain.

* Corresponding author: Tel.: +34-914972380. Fax: +34-914978255. E-mail:

tiziana.fornari@uam.es 


\begin{abstract}
Chrastil (1982) established that the solubility of a substance in a supercritical fluid can be correlated with the density of the pure supercritical gas. Recently, the solubility of supercritical fluids in different organic liquids was successfully correlated as a function solely of the supercritical fluid density, since we demonstrated that the supercritical fluid density also defines the solubility of the gas in the liquid phase.

In this work, the solubility of supercritical carbon dioxide in high molecular weight substances, such as high molecular weight paraffins, alcohols, fatty acids, fatty acid methyl and ethyl esters, has been correlated and constants provided. More than 20 binary systems comprising around 1000 solubility data points were correlated, obtaining regression coefficients greater than 0.96 and confirming the goodness of the densitydependent equation previously reported.
\end{abstract}

Keywords: solubility; supercritical fluids; vapor-liquid equilibria; Chrastil equation. 


\section{Introduction}

Stahl et al. ${ }^{1}$ firstly observed a close relationship between the solubility of a substance and the supercritical solvent density. In 1982, Chrastil $^{2}$ presented an equation based on the solvato complex model, which establishes a linear dependency, in logarithmic basis, between the solute solubility and the supercritical fluid density $\left(\rho_{S C F}\right)$. That is, a simple density-dependent equation was capable to correlate the equilibrium composition (i.e. the solubility) of a solute in the high pressure vapor phase of binary vapor-liquid or vapor-solid equilibria. Chrastil's equation was found to be applicable for dilute gas solutions (i.e. low concentration of solute in the supercritical phase) and thus, was widely employed to correlate the solubility of high molecular weight substances in supercritical carbon dioxide ${ }^{3-6}\left(\mathrm{SCCO}_{2}\right)$.

On the other side, the solubility of a gas in a liquid was conventionally described using Henry's law, which establishes that the amount of gas dissolved in a liquid is linearly proportional to its partial pressure. This law was found to be accurate for dilute liquid solutions (i.e. low amounts of gas dissolved in the liquid phase). As concentration or pressure increase, deviations from Henry's law become noticeable. Thus, this law is usually not capable to represent the solubility of a supercritical fluid in organic liquids. At high pressures, mixtures of $\mathrm{CO}_{2}+$ low molecular weight substances exhibit, in general, positive deviations to Henry's law while mixtures of $\mathrm{CO}_{2}+$ high molecular weight substances typically present negative deviations.

In a previous contribution ${ }^{7}$, we demonstrated that not only the composition of the vapor phase, as Chrastil ${ }^{2}$ established, but also the composition of the liquid phase is simply related with the SCF density. The solubility of a supercritical gas in a liquid (i.e. the SCF molar fraction in the liquid phase, $X_{S C F}$ ) was straightforwardly correlated with $\rho_{\text {SCF. }}$. Two semi-empirical density-dependent equations were presented which proved to 
be valid for mixtures presenting, respectively, positive and negative deviations to Henry’s law. In this work, the corresponding correlative constants are given to represent the solubility of $\mathrm{SCCO}_{2}$ in certain high molecular weight substances usually involved in technological applications of supercritical fluid processing.

\section{Theoretical background}

\section{High pressure solubility of solutes in supercritical gases: Chrastil's equation.}

At constant temperature, the relationship between the solute solubility and the supercritical solvent density was established as follows:

$$
\ln S_{S}=k^{\prime} \ln \left(\rho_{S C F}\right)+b^{\prime} \quad \text { (constant temperature) }
$$

$S_{S}$ is the solute solubility $(\mathrm{g} / \mathrm{L}), \rho_{S C F}$ is the density of the pure supercritical gas $(\mathrm{g} / \mathrm{L})$ and $k^{\prime}$ and $b^{\prime}$ are semi-empirical parameters.

As mentioned before, Eq. (1) was broadly employed in the literature to correlate the solubility of many compounds in supercritical gases, particularly in $\mathrm{SCCO}_{2}$. For example, Güçlü-Üstündag and Temelli ${ }^{3,4}$ reported $k^{\prime}$ and $b^{\prime}$ parameters for a large set of lipid-type substances.

\section{Solubility of supercritical fluids in organic liquids.}

In a previous work ${ }^{7}$ and based on a modification of Henry's law, we presented two semi-empirical density-dependent correlations to represent the solubility of a supercritical fluid in a liquid.

The SCF molar fraction in the liquid phase $\left(X_{S C F}\right)$ was given by the following relationship:

$$
\ln \left(X_{S C F}\right)=A \cdot \ln \left(\rho_{S C F}\right)+B \quad \text { (constant temperature) }
$$


for binary mixtures which exhibit positive deviations to Henry's law, that is, when $X_{S C F}$ $>K_{H} \cdot P_{S C F}$, being $P_{S C F}$ the gas partial pressure and $K_{H}$ Henry's constant.

In Eq. (2), $A$ and $B$ are constants which are regressed from $X_{S C F}$ experimental data, and $\rho_{\text {SCF }}$ is the SCF density given in $\mathrm{kg} / \mathrm{m}^{3}$.

The validity of Eq. (2) was demonstrated in previous work ${ }^{7}$ employing a large and varied set of vapor-liquid equilibria data including different organic liquids (alkanes, alkenes, alcohols, acids, ketones, esters, terpenes and aromatic compounds). The linear regression coefficients $\left(R^{2}\right)$ obtained when applying Eq. (2) to correlate $\ln \left(X_{S F C}\right)$ vs. $\ln \left(\rho_{S C F}\right)$ were greater than 0.98 when the mixtures exhibit positive deviations to Henry's law, but quite lower $R^{2}$ values were obtained in the case of mixture with negative deviations.

As mentioned before, most attractive applications of supercritical processes are related with high molecular weight substances, which in general exhibit negative deviations to Henry’s law. Thus, Eq. (2) was empirically modified as follows:

$$
\ln X_{S C F}=A^{*} \frac{\ln \left(\rho_{S C F}\right)}{P}+B^{*} \quad \text { (constant temperature) }
$$

were $P$ is the pressure (MPa), $\rho_{S C F}$ the supercritical fluid density $\left(\mathrm{kg} / \mathrm{m}^{3}\right)$ and $A^{*}$ and $B^{*}$ are the correlative constants which are regressed from experimental data. Eq. (3) establishes a linear relationship between $\ln \left(X_{S C F}\right)$ and $\ln \left(\rho_{S C F}\right) / P$ and was successfully applied to various binary mixtures of $\mathrm{CO}_{2}+$ high molecular weight substances ${ }^{7}$.

\section{Results and discussion}

\section{Regression coefficients obtained for the systems studied.}

Eq. (3) was used to correlate the solubility of $\mathrm{SCCO}_{2}$ in substances comprising certain families of compounds which are particularly interesting in supercritical $\mathrm{CO}_{2}$ 
processing. Tables 1 to 5 present the different systems investigated: high molecular weight paraffins (Table 1), high molecular weight alcohols (Table 2), fatty acids (Table 3), fatty acid methyl esters (Table 4) and fatty acid ethyl esters (Table 5). Also given in the tables are the source of the experimental solubility data employed ${ }^{8-23}$, the values of constants $A^{*}$ and $B^{*}$ obtained and the $R^{2}$ values resulted from the regression procedure.

As can be observed in the tables the $R^{2}$ values obtained when employing Eq. (3) to correlate the solubility of $\mathrm{CO}_{2}$ in high molecular weight alkanes and alcohols were greater than 0.97 . Figure 1 depicts the quality of the regression achieved for some selected $n$-alkanes and $n$-alcohols.

High regression coefficients were also obtained in the case of fatty acids (see Table 3) and fatty acid alkyl esters (Tables 4 and 5). As example, Figure 2 show the linear behavior obtained between $\ln \left(X_{\mathrm{CO} 2}\right)$ vs. $\ln \left(\rho_{\mathrm{CO} 2}\right) / P$ for some selected $\mathrm{CO}_{2}+$ fatty acid methyl ester mixtures.

In general, lower $R^{2}$ values resulted when merging in the regression procedure the solubility data reported by different authors. For example, the solubility of $\mathrm{CO}_{2}$ in methyl oleate at $333 \mathrm{~K}$ was correlated obtaining $R^{2}$ values of $0.954,0.997$ and 0.967 when the data reported, respectively, by Zou et al. ${ }^{15}$, Yu et al. ${ }^{16}$ and Chang et al. ${ }^{20}$ were separately considered. On the other hand, when the three sources of data were taken into account simultaneously, the $R^{2}$ obtained was somewhat lower (0.920). Similar results were obtained for other systems studied (see Tables 3 to 5). This is quite reasonable to expect due to the different equipments and procedures employed in the experimental determinations, which can produce systematic differences between the data reported. For example, in the case of the $\mathrm{CO}_{2}+$ oleic acid mixture at $313 \mathrm{~K}$, the $R^{2}$ values obtained considering separately the different sources of solubility data available ${ }^{14-16}$ were quite satisfactory but when merging all the experimental data available a quite 
poorer regression resulted $\left(R^{2}=0.826\right)$. Figure 3 shows that this result should be attributed to the high discrepancies found between the experimental data reported at 313 $\mathrm{K}$ and not to a failure of Eq. (3) to correlate the $\mathrm{CO}_{2}$ solubility data. Actually, considering the same system $\left(\mathrm{CO}_{2}+\right.$ oleic acid) and the same sources of experimental data $^{14-16}$ but a different temperature (333 $\mathrm{K}$ ), the $R^{2}$ values obtained were higher than 0.950 considering separately each source of solubility data or merging the data all together in the regression procedure (see Table 3).

\section{Comparison between the density-dependent correlation (Eq. 3) and the GC-EoS model in the calculation of $\mathrm{CO}_{2}$ solubility in high molecular weight substances.}

The liquid phase composition of the $\mathrm{CO}_{2}+$ high-molecular weight systems referred in Tables 1 to 5 were calculated using two different approaches: the density-dependent correlation given by Eq. (3) and the Group Contribution Equation of State (GC-EoS) model developed by Skjold-Jørgensen ${ }^{24}$.

Parameters $A^{*}$ and $B^{*}$ employed when applying Eq. (3) to calculate $X_{\mathrm{CO} 2}$ were those regressed in this work and are given in the corresponding tables.

With respect to the GC-EoS model, which is based on the group contribution approach,

the reader is referred to the work of Fornari ${ }^{25}$ where all pure group and binary group interaction parameters required (i.e. those corresponding to the $\mathrm{CO}_{2},-\mathrm{CH}_{3},-\mathrm{CH}_{2}$, $\mathrm{CH}_{2} \mathrm{OH}$, - $\mathrm{COOCH}_{3}$ and $-\mathrm{COOCH}_{2}$ - groups) are given. Pure component parameters, i.e. critical temperature $\left(T_{c}\right)$, critical pressure $\left(P_{c}\right)$ and critical hard sphere diameter $\left(d_{c}\right)$ are given in Table 6 for some of the high molecular weight substances studied. For high size-asymmetric mixtures, the $d_{c}$ parameter of the high molecular weight compound greatly affects the GC-EoS phase composition calculations ${ }^{25}$. Thus, this parameter was optimized in this work (see Table 6) in order to minimize the average absolute 
deviations $(A A D)$ between the experimental and calculated $\mathrm{CO}_{2}$ liquid mole fraction. The $A A D \%$ values are calculated as follows:

$A A D \%=\left(100 / N_{\text {exp }}\right) \sum\left|x_{C O 2}^{\text {exp }}-x_{C O 2}^{c a l}\right| / x_{C O 2}^{\text {exp }}$

In this way, the best GC-EoS correlation of the $X_{\mathrm{CO} 2}$ data that could be achieved is compared with Eq. (3) correlation.

Table 7 gives the $A A D \%$ resulted. As can be deduced from the table, Eq. (3) produce $A A D \%$ values lower (or of the same order of magnitude) than those resulted when applying the GC-EoS model in a correlative manner.

\section{Conclusions}

In this work, a Chrastil-type equation was applied to correlate the solubility of $\mathrm{SCCO}_{2}$ (i.e. the $\mathrm{CO}_{2}$ molar fraction, $X_{\mathrm{CO} 2}$ ) in high molecular weight liquid substances as a function of solely the $\mathrm{CO}_{2}$ density $\left(\rho_{\mathrm{CO} 2}\right.$ ). Based on experimental $X_{\mathrm{CO} 2}$ data from the literature, the parameters of the linear correlation between $\ln \left(X_{\mathrm{CO} 2}\right)$ and $\ln \left(\rho_{\mathrm{CO} 2}\right) / \mathrm{P}$ were given for 26 different substances comprising $n$-alkanes, n-alcohols, fatty acids and fatty acid alkyl (methyl and ethyl) esters. High linear regression coefficients were obtained for all systems studied, confirming the goodness of the density-dependent equation employed.

This new correlation permits the calculation of binary $\mathrm{CO}_{2}+$ substance liquid phase composition, circumventing the use of EoS based models (which are not always available or comprehensible for many people working in supercritical fluid processing) and with similar accuracy. Although this approach could never substitute the role of EoS models for process simulation, the correlation presented in this work provide a simple, fast and accurate manner to calculate the solubility of a supercritical fluid in a liquid. 


\section{Acknowledges}

The authors thank the financial support from Comunidad Autónoma de Madrid (ALIBIRD, project S2009-AGR-1469) and the Ministerio de Ciencia e Innovación (project 25506 FUN-C-FOOD), Spain. 


\section{Literature cited}

1. Stahl E, Schilz W, Schütz E, Willing E. A quick method for the microanalytical of the dissolving power of supercritical gases. Angew. Chem., Int. Ed. Engl. 1978; 17:731-738.

2. Chrastil J. Solubility of solids and liquids in supercritical gases. J. Phys. Chem. 1982; 86:3016-3021.

3. Güçlü-Üstündag Ö, Temelli F. Correlating the solubility behavior of fatty acids, mono-, di-, and triglycerides, and fatty acid esters in supercritical carbon dioxide. Ind. Eng. Chem. Res. 2000; 39:4756-4766.

4. Güçlü-Üstündag Ö, Temelli F. Correlating the solubility behavior of minor lipid components in supercritical carbon dioxide. J. Supercrit. Fluids 2004; 31:235-253.

5. Setianto WB, Nawi AH, Ab. Kadir MO. Application of Chrastil Model to the Virgin Coconut and Palm Kernel Oil Solubility in Supercritical Carbon Dioxide. International Conference on Environmental Research and Technology (ICERT). Cleaner tech, control, treatment \& remediation technique, pp. 921-925, 2008.

6. Del Valle JM, Aguilera JM. An improved equation for prediction the solubility of vegetable oils in supercritical $\mathrm{CO}_{2}$. Ind. Eng. Chem. Res. 1988; 27:1551-1553.

7. Fornari T, Hernández EJ, Reglero G. Solubility of supercritical gases in organic liquids. J. Supercrit. Fluids, in press.

8. Charoensombut-amon T, Martin RJ, Kobayashi R. Application of a generalized multiproperty apparatus to measure phase equilibrium and vapor phase densities of supercritical carbon dioxide in n-hexadecane systems up to $26 \mathrm{MPa}$. Fluid Phase Equilib. 1986; 31:89-104.

9. Sebastian HM, Simnick JJ, Lin H-M, Chao K-C. Vapor-liquid equilibrium in binary mixtures of carbon dioxide + n-decane and carbon dioxide + n-hexadecane. $J$. Chem. Eng. Data 1980; 25:138-140.

10. Nieuwoudt I, du Rand M. Measurement of phase equilibria of supercritical carbon dioxide and paraffins. J. Supercrit. Fluids 2002; 22:185-199.

11. Sato Y, Tagashira Y, Maruyama D, Takishima S, Masuoka H. Solubility of carbon dioxide in eicosane, docosane, tetracosane, and octacosane at temperatures from 323 to $473 \mathrm{~K}$ and pressures up to $40 \mathrm{MPa}$. Fluid Phase Equilibria 1998; 147:181-193. 
12. Chang CJ, Chiu K-L, Day C-Y. A new apparatus for the determination of $P-x-y$ diagrams and Henry's constants in high pressure alcohols with critical carbon dioxide. J. Supercrit. Fluids 1998, 12:223-237.

13. Jan D-S, Mai C-H, Tsai F-N. Solubility of Carbon Dioxide in 1-Tetradecanol, 1Hexadecanol, and 1-Octadecanol. J. Chem. Eng. Data 1994; 39:384-387.

14. Bharath R, Inomata H, Adschiri T, Arai K. Phase equilibrium study for the separation and fractionation of fatty oil components using supercritical carbon dioxide. Fluid Phase Equilibria 1992; 81:307-320.

15. Zou M, Yu ZR, Kashulines P, Rizvi SSH, Zollweg J. A. Fluid-liquid phase equilibria of fatty acids and fatty acid methyl esters in supercritical carbon dioxide. J. Supercrit. Fluids 1990; 3:23-28.

16. Yu ZR, Rizvi SSH, Zollweg J. A. Phase equilibrium of oleic acid, methyl oleate, and anhydrous milk fat in supercritical $\mathrm{CO}_{2}$. J. Supercrit. Fluids 1992; 5:114-122.

17. Inomata H, Kondo T, Hirohama S, Arai K, Suzuki Y, Konno M. Vapour-liquid equilibria for binary mixtures of carbon dioxide and fatty acid methyl esters. Fluid Phase Equilibria 1989; 46: 41-52.

18. Lockeman CA, Muñoz de Soto-Soliz S, Schlünder EU. High-pressure phase equilibria and densities of the binary system carbon dioxide/methyl laurate. Chemical Engineering and Processing 1995; 34:561-564.

19. Lockemann CA. High-pressure phase equilibria and densities of the binary mixtures carbon dioxide-oleic acid, carbon dioxide-methyl myristate, and carbon dioxidemethyl palmitate and of the ternary mixture carbon dioxide-methyl myristate-methyl palmitate. Chemical Engineering and Processing 1994; 33: 171- 187.

20. Chang C-MJ, Lee M-S, Li B-C, Chen P-Y. Vapor-Liquid Equilibria of $\mathrm{CO}_{2}$ with Four Unsaturated Fatty Acid Esters and Their Correlations at Elevated Pressures. Fluid Phase Equilibria 2005; 233:56-65.

21. Hwu W-H, Cheng J-S, Cheng K-W, Chen Y-P. Vapor-Liquid Equilibrium of Carbon Dioxide with Ethyl Caproate, Ethyl Caprylate and Ethyl Caprate at Elevated Pressures. J. Supercrit. Fluids 2004; 28:1-9.

22. Bharath R, Inomata H, Arai K, Shoji K, Noguchi Y. Vapor-liquid equilibria for binary mixtures of carbon dioxide and fatty acid ethyl esters. Fluid Phase Equilibria 1989; 50:315-327. 
23. Jaubert J-N, Borg P, Coniglio L, Barth D. Phase equilibria measurements and modeling of EPA and DHA ethyl esters in supercritical carbon dioxide. J. Supercrit. Fluids 2001; 20:145-155.

24. Skjold-Jørgensen S. Group Contribution Equation of State (GC-EOS): A Predictive Method for Phase Equilibrium Computations over Wide Ranges of Temperatures and Pressures up to 30 MPa. Ind. Eng. Chem. Res. 1988; 27:110-118.

25. Fornari T. Revision and summary of the group contribution equation of state parameter table: Application to edible oil constituents. Fluid Phase Equilibria 2007; 262:187-209.

26. Joback KG, Reid RC. Estimation of pure-component properties from group contributions. Chem. Eng. Commun. 1983; 57:233- 243. 
Table 1. Parameters $A^{*}$ and $B^{*}$ of Eq. (3) for different $\mathrm{CO}_{2}+$ high molecular weight alkane binary mixtures. $R^{2}$ : linear regression coefficient. $P$ is given in MPa and $\rho_{\mathrm{CO} 2}$ in $\mathrm{kg} / \mathrm{m}^{3}$.

\begin{tabular}{ccccccccccc}
\hline alkane & $T / \mathrm{K}$ & $\begin{array}{c}P \text { range } \\
\text { / MPa }\end{array}$ & $\begin{array}{c}X_{\mathrm{CO} 2} \\
\text { range }\end{array}$ & $\begin{array}{c}\rho_{\mathrm{CO} 2} \text { range } \\
/ \mathrm{kg} \cdot \mathrm{m}^{-3}\end{array}$ & $N_{\text {exp }}$ & $-A^{*}$ & $B^{*}$ & $R^{2}$ & ref. \\
\hline hexadecane & 313.2 & $0.69-12.25$ & $0.08-0.97$ & $12.0-725$ & 15 & 1.3455 & 0.6600 & 0.981 & 8 \\
& 323.2 & $0.69-17.00$ & $0.07-0.97$ & $11.6-740$ & 16 & 1.2509 & 0.4394 & 0.993 & 8 \\
& 333.2 & $0.69-21.73$ & $0.07-0.97$ & $11.2-749$ & 12 & 1.2926 & 0.3526 & 0.997 & 8 \\
& 343.2 & $0.69-25.82$ & $0.07-0.97$ & $10.9-747$ & 17 & 1.2826 & 0.2787 & 0.993 & 8 \\
eicosane & 462.9 & $2.00-5.08$ & $0.11-0.26$ & $23.4-61.1$ & 4 & 1.1215 & 0.4664 & 0.997 & 9 \\
& 315.9 & $7.74-24.90$ & $0.77-0.86$ & $234-868$ & 4 & 0.2521 & 0.0818 & 0.978 & 10 \\
& 320.6 & $8.64-22.31$ & $0.77-0.86$ & $274-823$ & 4 & 0.3142 & 0.0548 & 0.979 & 10 \\
& 329.6 & $10.43-25.89$ & $0.77-0.88$ & $346-812$ & 5 & 0.4287 & 0.0149 & 0.975 & 10 \\
& 339.1 & $10.43-24.65$ & $0.77-0.88$ & $283-754$ & 5 & 0.4999 & 0.0066 & 0.989 & 10 \\
& 348.3 & $11.50-28.79$ & $0.77-0.92$ & $295-755$ & 5 & 0.6435 & 0.0499 & 0.978 & 10 \\
& 357.1 & $18.50-30.16$ & $0.82-0.88$ & $528-731$ & 5 & 0.6041 & 0.0081 & 0.996 & 10 \\
& 423.2 & $12.28-38.48$ & $0.55-0.90$ & $185-592$ & 7 & 1.8522 & 0.1998 & 0.997 & 11 \\
\hline
\end{tabular}


Table 2. Parameters $A^{*}$ and $B^{*}$ of Eq. (3) for different $\mathrm{CO}_{2}+$ high molecular weight alcohol binary mixtures. $R^{2}$ : linear regression coefficient. $P$ is given in MPa and $\rho_{\mathrm{CO} 2}$ in $\mathrm{kg} / \mathrm{m}^{3}$.

\begin{tabular}{lcccccccccc}
\hline \multicolumn{1}{c}{ alcohol } & $T / \mathrm{K}$ & $\begin{array}{c}P \text { range } \\
/ \mathrm{MPa}\end{array}$ & $\begin{array}{c}X_{\mathrm{CO} 2} \\
\text { range }\end{array}$ & $\begin{array}{c}\rho_{\mathrm{CO} 2} \text { range } \\
/ \mathrm{kg} \cdot \mathrm{m}^{-3}\end{array}$ & $N_{\text {exp }}$ & $-A^{*}$ & $B^{*}$ & $R^{2}$ & ref. \\
\hline decanol & 308.2 & $2.23-7.75$ & $0.16-0.58$ & $42.9-320$ & 9 & 1.3249 & 0.3257 & 0.974 & 12 \\
& 318.2 & $2.18-10.47$ & $0.15-0.65$ & $40.0-559$ & 9 & 1.3571 & 0.3119 & 0.979 & 12 \\
tetradecanol & 328.2 & $2.89-15.17$ & $0.18-0.71$ & $52.4-659$ & 13 & 1.5315 & 0.3136 & 0.992 & 12 \\
& 373.0 & $1.01-5.07$ & $0.06-0.27$ & $14.7-81.9$ & 5 & 0.8122 & 0.6789 & 0.985 & 13 \\
hexadecanol & 423.0 & $1.01-5.07$ & $0.06-0.25$ & $12.8-68.5$ & 5 & 0.8449 & 0.7559 & 0.981 & 13 \\
& 573.0 & $1.01-5.07$ & $0.05-0.21$ & $9.4-47.6$ & 5 & 0.9956 & 0.8824 & 0.992 & 13 \\
& 473.0 & $1.01-5.07$ & $0.06-0.30$ & $14.7-82.0$ & 5 & 0.8594 & 0.5280 & 0.985 & 13 \\
& 473.0 & $1.01-5.07$ & $0.05-0.24$ & $11.4-59.4$ & 5 & 0.9275 & 0.7731 & 0.981 & 13 \\
& 573.0 & $1.01-5.07$ & $0.04-0.20$ & $9.4-47.6$ & 5 & 1.0659 & 0.8316 & 0.995 & 13 \\
& 373.0 & $1.01-5.07$ & $0.07-0.29$ & $14.7-82.0$ & 5 & 0.7781 & 0.6003 & 0.991 & 13 \\
& 473.0 & $1.01-5.07$ & $0.05-0.23$ & $11.4-59.4$ & 5 & 0.884 & 0.8459 & 0.991 & 13
\end{tabular}


Table 3. Parameters $A^{*}$ and $B^{*}$ of Eq. (3) for different $\mathrm{CO}_{2}+$ fatty acid binary mixtures. $R^{2}$ : linear regression coefficient. $P$ is given in MPa and $\rho_{C O 2}$ in $\mathrm{kg} / \mathrm{m}^{3}$.

\begin{tabular}{|c|c|c|c|c|c|c|c|c|c|}
\hline fatty acid & $T / \mathrm{K}$ & $\begin{array}{c}P \text { range } \\
/ \mathrm{MPa} \\
\end{array}$ & $\begin{array}{c}X_{\mathrm{CO} 2} \\
\text { range }\end{array}$ & $\begin{array}{c}\rho_{\mathrm{CO} 2} \text { range } \\
/ \mathrm{kg} \cdot \mathrm{m}^{-3}\end{array}$ & $N_{\text {exp }}$ & $-A^{*}$ & $B^{*}$ & $R^{2}$ & Ref. \\
\hline \multirow[t]{2}{*}{ caproic } & 313.2 & $2.76-5.29$ & $0.31-0.91$ & $53.4-347$ & 4 & 1.2810 & 0.6652 & 0.944 & 14 \\
\hline & 353.2 & $2.72-15.88$ & $0.17-0.87$ & $44.3-464$ & 6 & 1.5308 & 0.2808 & 0.962 & 14 \\
\hline \multirow[t]{2}{*}{ lauric } & 333.2 & $2.57-24.64$ & $0.24-0.88$ & $45.0-783$ & 10 & 1.0736 & 0.1496 & 0.994 & 14 \\
\hline & 353.0 & $5.33-27.65$ & $0.35-0.89$ & $95.2-721$ & 6 & 1.5046 & 0.224 & 0.997 & 14 \\
\hline \multirow[t]{2}{*}{ palmitic } & 353.2 & $15.36-30.52$ & $0.64-0.80$ & $443-751$ & 3 & 1.2618 & 0.0573 & 0.997 & 14 \\
\hline & 373.2 & $13.60-30.46$ & $0.57-0.80$ & $289-668$ & 4 & 1.5005 & 0.0654 & 0.967 & 14 \\
\hline \multirow[t]{9}{*}{ oleic } & 313.0 & $7.27-28.41$ & $0.66-0.81$ & $216-826$ & 6 & 0.4066 & 0.1111 & 0.999 & 15 \\
\hline & 313.2 & $10.17-30.00$ & $0.79-0.83$ & $642-911$ & 5 & 0.0997 & 0.1566 & 0.890 & 14 \\
\hline & 313.2 & $3.36-31.08$ & $0.36-0.81$ & $67.3-917$ & 9 & 0.7204 & 0.0069 & 0.933 & 16 \\
\hline & 313.0 & $3.36-31.08$ & $0.66-0.96$ & 67.3 - 917 & 20 & 0.6491 & 0.0088 & 0.826 & $14-16$ \\
\hline & 333.0 & $7.10-28.80$ & $0.65-0.80$ & $159-822$ & 6 & 0.5066 & 0.1028 & 0.964 & 15 \\
\hline & 333.2 & $10.73-30.02$ & $0.65-0.81$ & $338-831$ & 5 & 0.6408 & 0.0643 & 0.994 & 14 \\
\hline & 333.2 & $6.58-31.12$ & $0.51-0.82$ & $142-839$ & 8 & 0.8145 & 0.0069 & 0.955 & 16 \\
\hline & 333.2 & $6.58-31.12$ & $0.51-0.82$ & $142-839$ & 19 & 0.7681 & 0.0228 & 0.950 & $14-16$ \\
\hline & 353.2 & $11.06-29.34$ & $0.59-0.80$ & $259-739$ & 5 & 1.0707 & 0.0266 & 0.989 & 14 \\
\hline \multirow[t]{2}{*}{ linoleic } & 313.0 & $6.40-26.50$ & $0.72-0.82$ & $167-891$ & 6 & 0.2209 & 0.1506 & 0.991 & 15 \\
\hline & 333.0 & $6.34-27.14$ & $0.67-0.80$ & $135-808$ & 6 & 0.3361 & 0.145 & 0.963 & 15 \\
\hline
\end{tabular}


Table 4. Parameters $A^{*}$ and $B^{*}$ of Eq. (3) for different $\mathrm{CO}_{2}+$ fatty acid methyl esters binary mixtures. $R^{2}$ : linear regression coefficient. $P$ is given in $\mathrm{MPa}$ and $\rho_{\mathrm{CO} 2}$ in $\mathbf{k g} / \mathrm{m}^{3}$.

\begin{tabular}{|c|c|c|c|c|c|c|c|c|c|}
\hline $\begin{array}{c}\text { fatty acid } \\
\text { methyl } \\
\text { ester }\end{array}$ & $T / \mathrm{K}$ & $\begin{array}{c}P \text { range } \\
/ \mathrm{MPa}\end{array}$ & $\begin{array}{c}X_{\mathrm{CO} 2} \\
\text { range }\end{array}$ & $\begin{array}{c}\rho_{\mathrm{CO} 2} \text { range } \\
/ \mathrm{kg} \cdot \mathrm{m}^{-3}\end{array}$ & $N_{\text {exp }}$ & $-A^{*}$ & $B^{*}$ & $R^{2}$ & ref. \\
\hline \multirow[t]{4}{*}{ stearate } & 313.2 & $2.75-13.44$ & $0.50-0.93$ & $53.0-753$ & 8 & 0.6529 & 0.2578 & 0.976 & 17 \\
\hline & 323.2 & $2.15-16.32$ & $0.45-0.93$ & $38.5-759$ & 9 & 0.5894 & 0.1346 & 0.943 & 17 \\
\hline & 333.2 & $5.74-17.31$ & $0.57-0.90$ & $118-672$ & 4 & 0.9681 & 0.2596 & 0.997 & 17 \\
\hline & 343.2 & $6.18-19.73$ & $0.53-0.90$ & $121-654$ & 6 & 1.1349 & 0.2666 & 0.995 & 17 \\
\hline \multirow[t]{3}{*}{ laureate } & 313.0 & $3.00-8.00$ & $0.42-0.79$ & $58.9-279$ & 6 & 1.0312 & 0.5099 & 0.970 & 18 \\
\hline & 323.0 & $3.00-10.00$ & $0.28-0.88$ & $56.0-387$ & 8 & 1.4937 & 0.7065 & 0.992 & 18 \\
\hline & 333.0 & $2.00-12.00$ & $0.15-0.87$ & $34.2-437$ & 11 & 1.3275 & 0.4745 & 0.993 & 18 \\
\hline \multirow[t]{6}{*}{ myristate } & 313.2 & $2.26-9.17$ & $0.32-0.94$ & $42.5-527$ & 8 & 1.0532 & 0.5913 & 0.983 & 17 \\
\hline & 313.0 & $1.07-8.01$ & $0.10-0.76$ & $18.9-281$ & 9 & 0.9759 & 0.3345 & 0.992 & 19 \\
\hline & 313.0 & $1.07-9.17$ & $0.10-0.94$ & $18.9-527$ & 17 & 1.0607 & 0.5175 & 0.972 & 17,19 \\
\hline & 323.0 & $2.21-11.65$ & $0.34-0.92$ & $39.7-562$ & 7 & 0.8796 & 0.345 & 0.983 & 17 \\
\hline & 323.0 & $0.88-9.00$ & $0.14-0.94$ & $14.9-286$ & 13 & 0.7517 & 0.2906 & 0.989 & 19 \\
\hline & 323.0 & $0.88-11.65$ & $0.14-0.94$ & $14.9-562$ & 20 & 0.7577 & 0.2783 & 0.982 & 17,19 \\
\hline \multirow[t]{10}{*}{ palmitate } & 313.2 & $2.48-11.10$ & $0.40-0.95$ & $47.2-288$ & 12 & 0.9019 & 0.4496 & 0.980 & 17 \\
\hline & 313.0 & $1.22-10.00$ & $0.19-0.91$ & $21.7-633$ & 11 & 0.8018 & 0.3526 & 0.989 & 19 \\
\hline & 313.0 & $1.22-11.10$ & $0.19-0.95$ & $21.7-633$ & 23 & 0.8264 & 0.3816 & 0.985 & 17,19 \\
\hline & 323.0 & $2.12-13.49$ & $0.33-0.92$ & $37.9-656$ & 7 & 0.8286 & 0.2787 & 0.984 & 17 \\
\hline & 323.0 & $1.06-13.00$ & $0.21-0.93$ & $18.1-639$ & 15 & 0.7162 & 0.2293 & 0.966 & 19 \\
\hline & 323.0 & $1.06-13.49$ & $0.21-0.93$ & $18.1-656$ & 22 & 0.7314 & 0.2294 & 0.964 & 17,19 \\
\hline & 333.2 & $2.53-15.90$ & $0.36-0.91$ & $44.2-635$ & 11 & 0.8879 & 0.2491 & 0.984 & 17 \\
\hline & 333.0 & $3.17-13.00$ & $0.44-0.85$ & $57.0-509$ & 10 & 0.8022 & 0.1672 & 0.978 & 19 \\
\hline & 333.0 & $2.53-15.90$ & $0.36-0.91$ & $44.2-635$ & 21 & 0.8635 & 0.2236 & 0.979 & 17,19 \\
\hline & 343.0 & $1.95-18.29$ & $0.26-0.91$ & $32.1-620$ & 10 & 0.9045 & 0.167 & 0.978 & 17 \\
\hline
\end{tabular}




\begin{tabular}{lccccccccc} 
oleate & 313.0 & $2.86-12.51$ & $0.48-0.94$ & $55.6-734$ & 12 & 0.8102 & 0.3919 & 0.984 & 20 \\
& 313.0 & $2.91-10.77$ & $0.42-0.89$ & $56.8-674$ & 4 & 0.9405 & 0.4382 & 0.996 & 16 \\
& 313.0 & $4.65-13.37$ & $0.60-0.94$ & $102-753$ & 6 & 0.9358 & 0.4212 & 0.960 & 15 \\
& 313.0 & $2.86-13.37$ & $0.42-0.94$ & $55.6-753$ & 22 & 0.8724 & 0.4107 & 0.961 & $15,16,20$ \\
linoleate & 333.0 & $5.62-18.03$ & $0.60-0.94$ & $114-689$ & 13 & 0.8738 & 0.281 & 0.967 & 20 \\
& 333.0 & $7.36-13.69$ & $0.64-0.84$ & $168-547$ & 4 & 1.1303 & 0.3556 & 0.997 & 16 \\
& 333.0 & $4.05-18.96$ & $0.53-0.92$ & $75.8-707$ & 7 & 0.7985 & 0.1632 & 0.954 & 15 \\
& 333.0 & $4.05-18.96$ & $0.53-0.94$ & $75.8-707$ & 24 & 0.9027 & 0.2647 & 0.920 & $15,16,20$ \\
& 313.0 & $2.86-11.82$ & $0.52-0.94$ & $55.7-715$ & 12 & 0.7432 & 0.3574 & 0.978 & 20 \\
& 313.0 & $4.36-13.10$ & $0.59-0.95$ & $93.7-747$ & 6 & 0.9009 & 0.4029 & 0.968 & 15 \\
& 313.0 & $2.82-13.10$ & $0.52-0.95$ & $55.7-747$ & 18 & 0.7561 & 0.3443 & 0.930 & 15,20 \\
& 333.0 & $5.62-18.03$ & $0.61-0.95$ & $114-689$ & 14 & 0.8694 & 0.2827 & 0.970 & 20 \\
& 333.0 & $3.81-20.29$ & $0.50-0.94$ & $70.5-730$ & 7 & 0.7888 & 0.1652 & 0.975 & 15 \\
& 333.0 & $3.81-20.29$ & $0.50-0.95$ & $70.5-730$ & 21 & 0.8417 & 0.244 & 0.927 & 15,20 \\
\hline
\end{tabular}


Table 5. Parameters $A^{*}$ and $B^{*}$ of Eq. (3) for different $\mathrm{CO}_{2}+$ fatty acid ethyl esters binary mixtures. $R^{2}$ : linear regression coefficient. $P$ is given in MPa and $\rho_{\mathrm{CO} 2}$ in $\mathrm{kg} / \mathrm{m}^{3}$.

\begin{tabular}{|c|c|c|c|c|c|c|c|c|c|}
\hline $\begin{array}{l}\text { fatty acid } \\
\text { ethyl ester }\end{array}$ & $T / \mathrm{K}$ & $\begin{array}{c}P \text { range } \\
/ \mathrm{Mpa}\end{array}$ & $\begin{array}{c}X_{\mathrm{CO} 2} \\
\text { range }\end{array}$ & $\begin{array}{c}\rho_{\mathrm{CO} 2} \text { range } \\
/ \mathrm{kg} \cdot \mathrm{m}^{-3}\end{array}$ & $N_{\text {exp }}$ & $-A^{*}$ & $B^{*}$ & $R^{2}$ & ref. \\
\hline \multirow{3}{*}{ Caproato } & 308.2 & $1.70-6.46$ & $0.28-0.85$ & $31.7-183$ & 8 & 0.8923 & 0.4966 & 0.988 & 21 \\
\hline & 318.2 & $1.70-7.82$ & $0.23-0.85$ & $30.4-229$ & 10 & 0.9894 & 0.4472 & 0.985 & 21 \\
\hline & 328.2 & $1.73-9.22$ & $0.20-0.84$ & $29.9-268$ & 12 & 1.0358 & 0.3862 & 0.986 & 21 \\
\hline \multirow[t]{3}{*}{ Caprylato } & 308.2 & $1.75-7.17$ & $0.27-0.89$ & $32.7-235$ & 9 & 0.9297 & 0.5128 & 0.984 & 21 \\
\hline & 318.2 & $1.69-7.82$ & $0.24-0.80$ & $30.4-229$ & 10 & 0.9236 & 0.3672 & 0.987 & 21 \\
\hline & 328.2 & $1.69-9.21$ & $0.20-0.81$ & $29.2-268$ & 12 & 0.9907 & 0.3258 & 0.987 & 21 \\
\hline \multirow[t]{3}{*}{ Caprato } & 308.2 & $1.66-7.10$ & $0.25-0.84$ & $31.0-229$ & 9 & 0.9151 & 0.4528 & 0.979 & 21 \\
\hline & 318.2 & $1.69-7.89$ & $0.22-0.77$ & $30.4-233$ & 10 & 0.9295 & 0.3301 & 0.988 & 21 \\
\hline & 328.2 & $1.69-9.21$ & $0.20-0.77$ & $29.2-268$ & 11 & 0.9633 & 0.2587 & 0.985 & 21 \\
\hline \multirow[t]{3}{*}{ Stearate } & 313.2 & $2.84-13.22$ & $0.45-0.91$ & $55.2-748$ & 9 & 0.8011 & 0.3322 & 0.975 & 22 \\
\hline & 323.2 & $2.70-15.94$ & $0.45-0.90$ & $49.6-721$ & 9 & 0.6837 & 0.1702 & 0.981 & 22 \\
\hline & 333.2 & $3.50-18.26$ & $0.44-0.91$ & $63.8-693$ & 10 & 0.8839 & 0.2290 & 0.999 & 22 \\
\hline \multirow[t]{3}{*}{ Oleate } & 313.2 & $2.98-12.50$ & $0.52-0.91$ & $58.4-732$ & 9 & 0.7226 & 0.2959 & 0.961 & 22 \\
\hline & 323.2 & $2.08-15.95$ & $0.36-0.92$ & $37.1-722$ & 13 & 0.7311 & 0.2084 & 0.979 & 22 \\
\hline & 333.2 & $3.14-18.62$ & $0.39-0.96$ & $56.3-700$ & 15 & 0.9432 & 0.2580 & 0.993 & 22 \\
\hline \multirow[t]{3}{*}{ Linoleate } & 313.2 & $2.00-12.09$ & $0.35-0.94$ & $31.7-721$ & 8 & 0.7816 & 0.3455 & 0.986 & 22 \\
\hline & 323.2 & $1.97-15.28$ & $0.31-0.91$ & $35.0-707$ & 12 & 0.7964 & 0.2509 & 0.991 & 22 \\
\hline & 333.2 & $2.03-16.97$ & $0.29-0.90$ & $34.8-664$ & 13 & 0.8390 & 0.2051 & 0.988 & 22 \\
\hline \multirow[t]{6}{*}{ EPA } & 303.1 & $6.00-11.80$ & $0.75-0.90$ & $171-806$ & 5 & 0.5286 & 0.2103 & 0.855 & 23 \\
\hline & 313.1 & $4.24-15.27$ & $0.59-0.94$ & $90.3-786$ & 13 & 0.7339 & 0.2846 & 0.968 & 20 \\
\hline & 313.1 & $3.04-14.87$ & $0.54-0.92$ & $59.8-779$ & 10 & 0.6156 & 0.2048 & 0.971 & 22 \\
\hline & 313.1 & $6.50-13.90$ & $0.75-0.90$ & $171-762$ & 5 & 0.5628 & 0.1637 & 0.974 & 23 \\
\hline & 313.1 & $3.04-15.27$ & $0.54-0.94$ & $59.8-786$ & 28 & 0.6520 & 0.2291 & 0.961 & $20,22,23$ \\
\hline & 323.1 & $2.87-16.90$ & $0.53-0.91$ & $53.2-741$ & 12 & 0.5627 & 0.1240 & 0.969 & 22 \\
\hline
\end{tabular}




\begin{tabular}{cccccccccc} 
& 323.1 & $8.00-16.50$ & $0.75-0.90$ & $219-732$ & 5 & 0.6238 & 0.1449 & 0.961 & 23 \\
& 323.1 & $2.87-16.90$ & $0.53-0.91$ & $53.2-741$ & 17 & 0.5621 & 0.1203 & 0.967 & 22,23 \\
333.1 & $2.86-20.79$ & $0.28-0.93$ & $50.7-737$ & 14 & 1.0598 & 0.3269 & 0.968 & 20 \\
DHA & 333.1 & $5.17-19.04$ & $0.61-0.89$ & $103-708$ & 12 & 0.6932 & 0.1429 & 0.987 & 22 \\
& 333.1 & $9.00-18.90$ & $0.75-0.90$ & $235-705$ & 4 & 0.7310 & 0.1617 & 0.996 & 23 \\
& 333.1 & $2.86-20.79$ & $0.28-0.93$ & $50.7-737$ & 30 & 0.9883 & 0.2893 & 0.950 & $20,22,23$ \\
& 343.1 & $10.20-21.20$ & $0.75-0.90$ & $256-682$ & 5 & 0.7335 & 0.1183 & 0.965 & 23 \\
& 353.1 & $14.10-23.20$ & $0.79-0.90$ & $388-659$ & 4 & 0.7899 & 0.1116 & 0.936 & 23 \\
& 313.1 & $4.24-18.03$ & $0.53-0.94$ & $90.3-822$ & 13 & 0.7454 & 0.2732 & 0.881 & 20 \\
& 313.1 & $1.87-16.85$ & $0.48-0.90$ & $34.5-807$ & 12 & 0.4432 & 0.1038 & 0.984 & 22 \\
& 313.1 & $4.70-17.50$ & $0.64-0.95$ & $104-815$ & 6 & 0.6181 & 0.1917 & 0.992 & 23 \\
& 313.1 & $1.87-18.03$ & $0.48-0.95$ & $34.5-822$ & 31 & 0.5126 & 0.1415 & 0.892 & $20,22,23$ \\
& 323.1 & $2.29-17.38$ & $0.55-0.89$ & $41.2-766$ & 12 & 0.3850 & 0.0174 & 0.966 & 22 \\
& 323.1 & $5.50-20.00$ & $0.64-0.95$ & $119-785$ & 7 & 0.6906 & 0.1745 & 0.993 & 23 \\
& 323.1 & $2.29-20.00$ & $0.55-0.95$ & $41.2-785$ & 19 & 0.4317 & 0.0472 & 0.920 & 22,23 \\
& 333.1 & $7.00-23.54$ & $0.67-0.94$ & $156-772$ & 13 & 0.6659 & 0.1283 & 0.977 & 20 \\
& 333.1 & $2.79-19.22$ & $0.48-0.88$ & $49.3-711$ & 8 & 0.5746 & 0.0688 & 0.993 & 22 \\
& 333.1 & $2.79-23.54$ & $0.48-0.94$ & $49.3-772$ & 21 & 0.6038 & 0.0949 & 0.984 & 20,22 \\
\hline
\end{tabular}


Table 6. Pure component parameters employed in the GC-EoS calculations.

\begin{tabular}{lcccc}
\hline & $T_{c} / \mathrm{K}$ & $P_{c} / \mathrm{MPa}$ & $d_{c} \mathrm{~cm} \cdot \mathrm{mol}^{-1}$ & $\begin{array}{c}\text { Ref. for } T_{c} \text { and } \\
P_{c} \text { values }\end{array}$ \\
\hline hexadecane & 720.6 & 1.42 & 7.174 & 10 \\
eicosane & 768.0 & 1.16 & 8.072 & 10 \\
decanol & 687.0 & 2.22 & 5.995 & 12 \\
hexadecanol & 724.2 & 1.57 & 7.186 & 13 \\
oleic acid & 781.0 & 1.37 & 8.056 & 26 \\
methylmyristate & 707.9 & 14.2 & 7.273 & 26 \\
methyloleate & 767.0 & 10.5 & 7.969 & 26 \\
ethyloleate & 784.2 & 1.05 & 8.049 & 26 \\
\hline
\end{tabular}


Table 7. Comparison between the average absolute deviations (AAD\%) obtained in the calculation of $\mathrm{CO}_{2}$ solubility (mole fractions) in liquid high-molecular weight substances using the density-dependent correlation (Eq. 3) and the GC-EoS model.

\begin{tabular}{lccc}
\hline & $\begin{array}{c}\text { GC-EoS } \\
\text { correlation }\end{array}$ & $\begin{array}{c}\text { Eq. (3) } \\
\text { correlation }\end{array}$ & $\begin{array}{c}\text { Ref. for } \\
\text { experimental data }\end{array}$ \\
\hline hexadecane & 6.96 & 2.30 & 8,9 \\
eicosane & 1.98 & 2.73 & 10 \\
decanol & 9.63 & 4.63 & 12 \\
hexadecanol & 14.66 & 5.65 & 13 \\
oleic acid & 1.97 & 2.06 & 14 \\
methylmyristate & 11.12 & 6.16 & 17,19 \\
methyloleate & 4.22 & 3.71 & $15,16,20$ \\
ethyloleate & 2.94 & 2.30 & 22 \\
\hline
\end{tabular}




\section{FIGURE CAPTIONS}

FIGURE 1. Linear correlation between $\ln \left(X_{\mathrm{CO} 2}\right)$ and $\ln \left(\rho_{\mathrm{CO} 2}\right) / \mathrm{P}$ (Eq. 3) for binary mixtures of $\mathrm{CO}_{2}$ with high molecular weight alkanes. (ם) n-hexadecane ${ }^{8}, 323.15 \mathrm{~K}$; (A) eicosane $^{10}$, 339.1 K; (O) tetracosane ${ }^{11}$, $423.2 \mathrm{~K}$.

FIGURE 2. Linear correlation between $\ln \left(X_{\mathrm{CO} 2}\right)$ and $\ln \left(\rho_{\mathrm{CO} 2}\right) / \mathrm{P}$ (Eq. 3) for binary mixtures of $\mathrm{CO}_{2}$ with fatty acid methyl esters. ( $\left.\boldsymbol{\square}\right)$ methyl palmitate ${ }^{17}$, $323.15 \mathrm{~K}$; ( $\mathbf{\Delta}$ ) methyl laureate $^{18}$, $323 \mathrm{~K}$; $(\bigcirc)$ methyl oleate $^{20}$, $333 \mathrm{~K}$; $(\times)$ methyl linoleate ${ }^{15}$, $333 \mathrm{~K}$.

FIGURE 3. Solubility of $\mathrm{SCCO}_{2}$ in oleic acid at $313 \mathrm{~K}$. (a) Comparison between the data reported by different authors: $(\boldsymbol{O})$ Zou et al. ${ }^{15} ;(\boldsymbol{\Delta})$ Bharath et al. ${ }^{14} ;(\bullet)$ Yu et al. ${ }^{16}$. (b) Linear correlation between $\ln \left(X_{\mathrm{CO} 2}\right)$ and $\ln \left(\rho_{\mathrm{CO} 2}\right) / \mathrm{P}$ (Eq. 3) obtained considering separately each source of experimental data. 


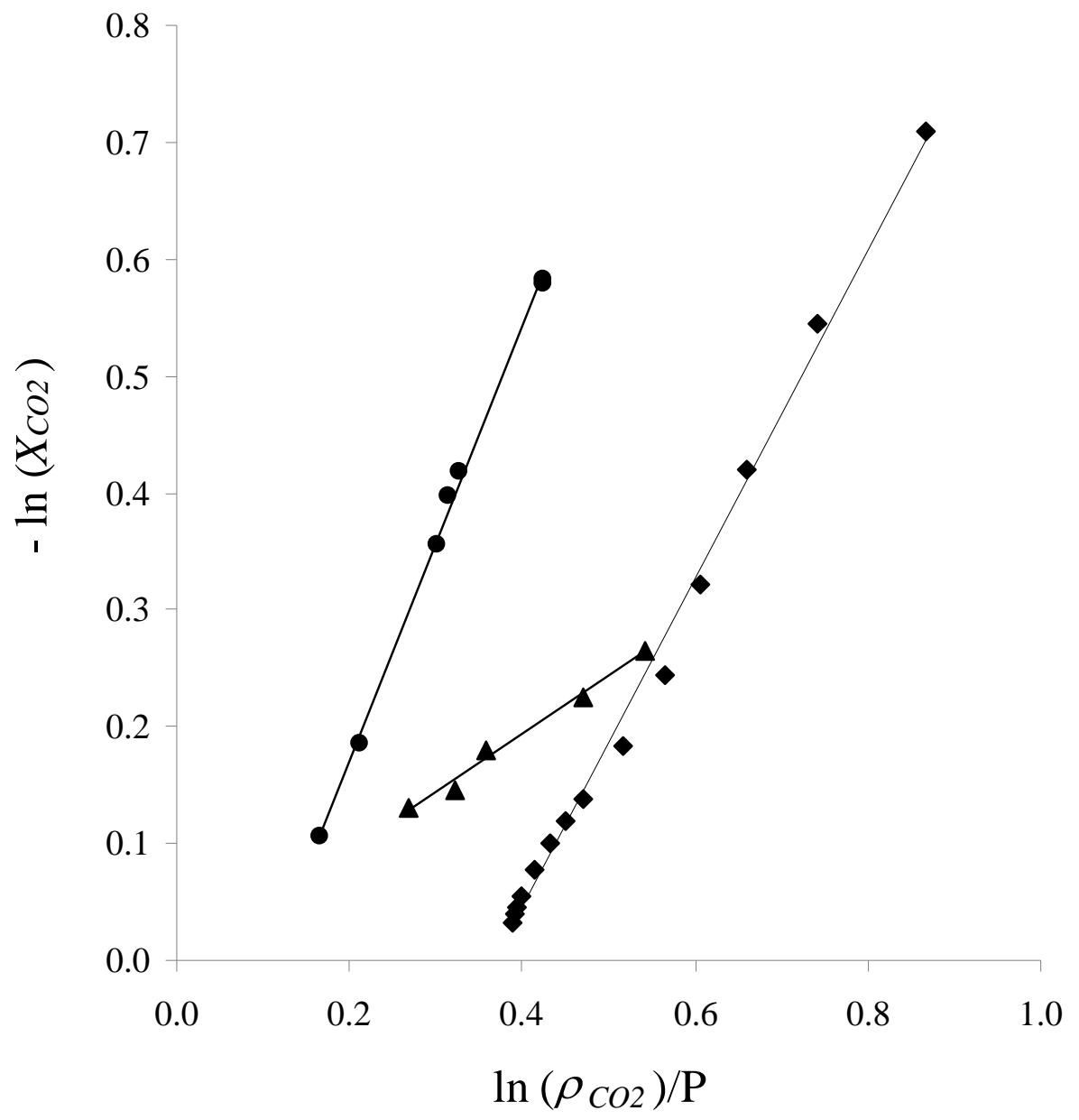

FIGURE 1. Linear correlation between $\ln \left(X_{\mathrm{CO} 2}\right)$ and $\ln \left(\rho_{\mathrm{CO} 2}\right) / \mathbf{P}(\mathrm{Eq} .3)$ for binary mixtures of $\mathrm{CO}_{2}$ with high molecular weight alkanes. ( $\square$ ) n-hexadecane ${ }^{8}, 323.15 \mathrm{~K}$; (A) eicosane $^{10}$, $339.1 \mathrm{~K}$; (O) tetracosane $^{11}, 423.2 \mathrm{~K}$. 


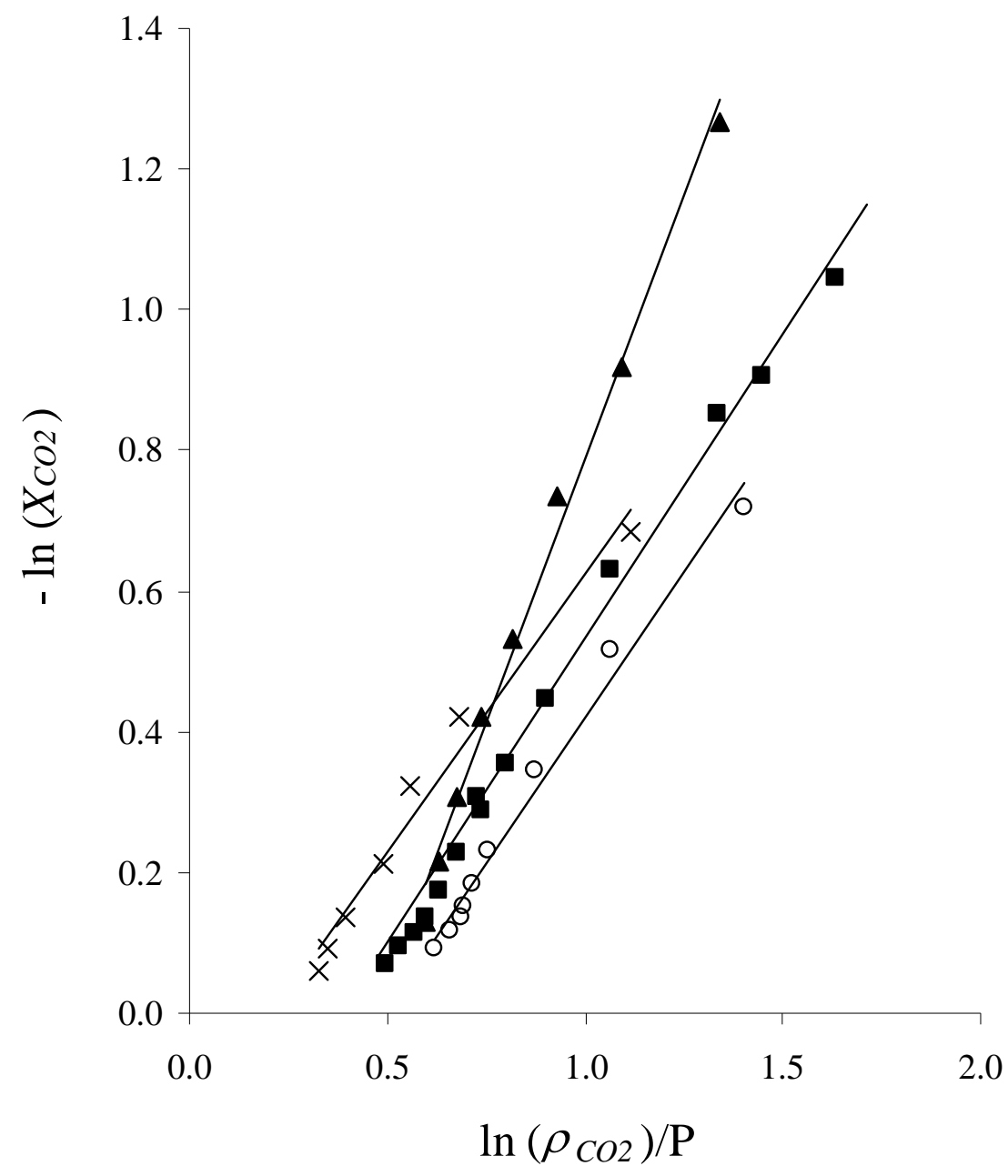

FIGURE 2. Linear correlation between $\ln \left(X_{\mathrm{CO} 2}\right)$ and $\ln \left(\rho_{\mathrm{CO} 2}\right) / \mathbf{P}(\mathrm{Eq} .3)$ for binary mixtures of $\mathrm{CO}_{2}$ with fatty acid methyl esters. ( $\square$ ) methyl palmitate ${ }^{17}, 323.15 \mathrm{~K}$; (A) methyl laureate ${ }^{18}, 323 \mathrm{~K}$; (O) methyl oleate ${ }^{20}, 333 \mathrm{~K}$; (X) methyl linoleate $^{15}$, $333 \mathrm{~K}$. 

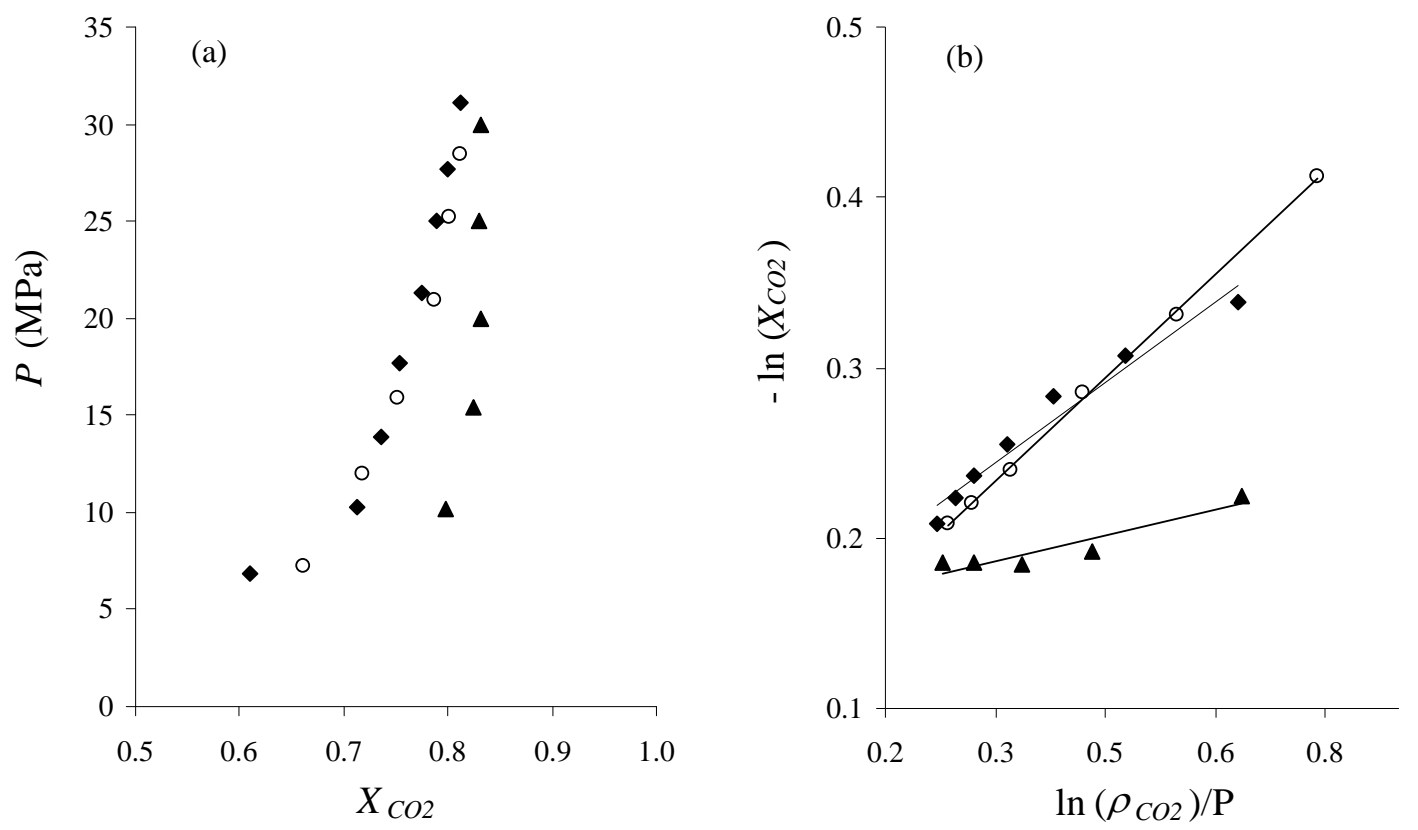

FIGURE 3. Solubility of $\mathrm{SCCO}_{2}$ in oleic acid at $313 \mathrm{~K}$. (a) Comparison between the data reported by different authors: $(\odot)$ Zou et al. ${ }^{15}$; (A) Bharath et al. ${ }^{14}$; $(\diamond)$ Yu et al. ${ }^{16}$. (b) Linear correlation between $\ln \left(X_{\mathrm{CO} 2}\right)$ and $\ln \left(\rho_{\mathrm{CO} 2}\right) / \mathbf{P}$ (Eq. 3) obtained considering separately each source of experimental data. 